\title{
Technological innovation and neurosurgery
}

\author{
Mario Ammirati ${ }^{1,2}$ (])
}

Received: 13 April 2021 / Accepted: 19 April 2021 / Published online: 8 June 2021

(c) The Author(s), under exclusive licence to Springer-Verlag GmbH Austria, part of Springer Nature 2021

Innovation is part and parcel of neurosurgery, and inquisitive/innovative mind is certainly a common trait of many neurosurgeons.

Hundreds of new products are introduced into the neurosurgical marketplace, including Spine, every year. The goal of the manufacturers is that of making a profit by selling as many as possible of these new products at the highest price the market can bear. Many of these gadgets do not subtend a paradigm shift, although from a market standpoint a paradigm shift is the most desirable outcome the manufacturer may hope for.

When a paradigm shift is proposed such as going from microscope to endoscope or from endoscope to exoscope, then the first and foremost question to be addressed should be "what is the clinical problem the innovation is poised to address?". If that is not strongly addressed upfront, then the innovation risks to become an answer in search of a problem. That is where the IDEAL recommendations or similar frameworks are helpful [2].

In reality, many neurosurgical innovations do not subtend a paradigm shift and are presented to the market, once cleared by the appropriate regulatory board, as an option or to use a commonly referred to phrase as "another tool in the neurosurgeon's armamentarium".

Even then, the safety claim of technical innovations/new procedures needs to be critically assessed [1].
Mario Ammirati

lemoko60@me.com

1 Center for Biotechnology Department of Biology, College of Science and Technology, Temple University, Philadelphia, PA, USA

2 Innovative Neurotherapeutic Research Program Sbarro Health Organization at Temple University, 1900 North 12th Street, Biolife Science Building, Suite 431, Philadelphia, PA 19122, USA
Cooperation with industry is fundamental; however, the risks of such cooperation need to be first acknowledged and then properly managed.

We appreciate all the points made by Drs. Roethe and colleagues, and we agree in principle with all of them. We also recognize the rigor/exactness of her work.

We all want and wish for the right innovation, that is the one that responds to a clinical need and that has been properly tested/verified, to disrupt established neurosurgical procedures/techniques; we should all want all other innovations to be recognized for what they are, often purely marketing exercises.

\section{References}

1. Khan AA, Haines SJ (2021) Claims of safety in neurosurgical literature: we shouldn't call something safe without strong justification. Neurosurgery 88(3):468-476

2. McCulloch P, Altman DG, Campbell WB, Flum DR, Glasziou P, Marshall JC, Nicholl J (2009) No surgical innovation without evaluation: the IDEAL recommendations. Lancet 374(9695):1105-1112

Publisher's note Springer Nature remains neutral with regard to jurisdictional claims in published maps and institutional affiliations. 